\title{
UMA PROPOSTA PARA A EDUCAÇÃO BÁSICA: 0 CONTO AFRICANO DE LÍNGUA PORTUGUESA EM SALA DE AULA ${ }^{1}$
}

Demétrio Alves Paz (UFFS)

Pablo Lemos Berned (UFFS)

Resumo: A partir da leitura de contos representativos das literaturas de Angola, Cabo Verde, Guiné-Bissau, Moçambique e São Tomé e Príncipe em cursos de extensão voltados para professores da Educação Básica e estudantes de Letras, desenvolvemos um trabalho para conquistar leitores e introduzi-los ao estudo e apreciação de textos literários. Nosso foco direcionou-se para a apresentação de expressões literárias dos Países Africanos de Língua Oficial Portuguesa (PALOP), raramente apreciados nos ambientes escolares. Dessa forma, foram estimulados momentos de leitura e debates sobre os textos, assim como a apropriação de contextos históricos e culturais, ressaltando aproximações e diferenças com nosso público do interior do sul do Brasil. Com isso, foram elaboradas sequências didáticas a partir dos trabalhos desenvolvidos nos cursos, dando visibilidade a autores e obras de reconhecida qualidade estética, mas de circulação restrita mesmo nos meios acadêmicos brasileiros.

Palavras-chave: Conto; Literaturas Africanas de Língua Portuguesa; Ensino.

Abstract: From the reading of representative short stories of literature from Angola, Cape Verde, Guinea-Bissau, Mozambique and São Tomé and Príncipe in extension courses designed for teachers of Secondary Schools and Language students, we developed a task to seduce readers and introduce them to the study and appreciation of literary texts. The focus was the presentation of literary expressions of Portuguesespeaking African countries (PALOP), rarely valued in the classroom. In this way, there were stimulated reading moments and debates about the texts, as well as the appropriation of historical and cultural contexts, highlighting the similitudes and differences with our audience in the south of Brazil. Therefore, there were elaborated didactical sequences

1 Título do artigo em inglês: "A proposition for the basic education: african short story in portuguese language in the classroom" 
from the assignment developed in the courses, obtaining visibility to the authors and works of renowned esthetical quality, but with restrained circulation even in the Brazilian academic space.

Keywords: Short story; African Literatures in Portuguese Language; Teaching.

\section{LITERATURAS AFRICANAS DE LÍNGUA PORTUGUESA EM SALA DE AULA: O CONTO COMO PROPOSTA}

Nos anos de 2013 e 2014 coordenamos e ministramos, respectivamente, os projetos de extensão "O conto de língua portuguesa em sala de aula" e "O conto contemporâneo de língua portuguesa em sala de aula" na UFFS para professores da Educação Básica das escolas das redes estadual, municipal e privada do município de Cerro Largo - RS. Nas duas ocasiões percebemos que, ao trabalhar narrativas de autores contemporâneos, havia uma melhor participação e envolvimento não só na leitura e apreciação dos textos como também na discussão deles. Os dois projetos estão ligados ao projeto de pesquisa "O conto em língua portuguesa em sala de aula" (aprovado no edital FAPERGS 03/2012 - ARD).

Notamos, com os projetos, que a produção literária a partir da década de 50 do século XX representa de maneira mais clara os problemas e os dilemas da contemporaneidade, assim como utiliza uma linguagem mais próxima dos jovens leitores. Selecionamos contos de autores africanos não só para apresentar um gênero representativo das 
cinco literaturas de língua portuguesa, mas também para possibilitar aos jovens a leitura de textos não tão divulgados na Educação Básica.

Metodologicamente, os nossos projetos são devedores a duas obras: Letramento Literário, de Rildo Cosson (2011), e Literaturas africanas e afro-brasileira na prática pedagógica, de Iris M.C. Amâncio, Nilma L. Gomes e Miriam L. S. Jorge (2014). No que diz respeito aos cursos de extensão, tentamos propiciar "[...] um espaço de interação entre as dimensões pessoais e profissionais em que aos professores é permitido apropriar-se dos próprios processos de formação e dar-lhes um sentido no quadro de suas histórias de vida" (GOMES, 2014, p.23).

Da mesma forma, ao levarmos em conta o objetivo principal, que é a prática pedagógica, pautamo-nos nas quatro práticas para a concretização do letramento literário na escola, tal como proposto por Graça Paulino e Rildo Cosson (2009, p.74-76): estabelecer uma comunidade de leitores; ampliar e consolidar a relação dos alunos com a literatura; construir um repertório de leituras; e ofertar espaços para a criação e circulação de textos.

O letramento literário implica a formação de espaços para que a leitura seja presente e compartilhada na 
escola, favorecendo o acesso pela juventude à tradição da Literatura e também incentivando a formação de um rol de leituras individuais por meio da oferta de uma seleção variada, inclusive em diferentes suportes (internet, e-book, oralidade). Nessa perspectiva, ao professor cabe o papel de promover tanto a relação dos textos com o mundo, quanto os diálogos que podem ser feitos com outras formas de arte. Ao aproximar os estudantes da linguagem literária, recorrendo à formação de novos textos pelos alunos, tornamos a leitura mais significativa e mais presente no cotidiano.

Os projetos de extensão desenvolveram-se por meio de cursos de 80 horas, cujo propósito foi o de promover a formação continuada de professores da Educação Básica e docentes em formação da UFFS, assim como orientar a elaboração de propostas de trabalho a partir do Letramento Literário. Algumas delas, aplicadas nas próprias turmas dos participantes dos cursos. Além disso, os projetos tiveram por objetivos: instrumentalizar professores para o trabalho com conto em sala de aula; divulgar a literatura de língua portuguesa por meio de seus contistas; incentivar o hábito da leitura literária; identificar contos para serem trabalhados com alunos do 6으 ano do Ensino Fundamental ao 3ㅇ ano do Ensino Médio. 
Previamente os textos eram enviados para os participantes e nos encontros líamos excertos dos textos e discutíamos formas de usá-los em sala de aula, tendo como base a proposta de letramento literário de Rildo Cosson (2011). As sequências didáticas que surgiram foram aplicadas tanto por bolsistas do PIBID, quanto por alunos de Letras em seus estágios, assim como pelos professores em sala de aula. Os professores ministrantes seguiam a sequência básica do letramento literário. Havia uma motivação, uma introdução, a leitura e, ao invés da interpretação, fizemos a discussão de como trabalhar em aula os contos com os alunos. Como quase todos os autores africanos eram desconhecidos pelo público, assim como algumas expressões usadas, havia um momento de contextualização histórica das obras, de elucidação de vocabulário e de expressões usadas nos textos. Depois, debatemos formas de usá-los com os alunos.

Em relação à motivação, quase sempre o foco foi o de apresentar dados sobre o país do escritor e as relações que podem ser feitas com o Brasil. No que diz respeito à apresentação, como as obras são difíceis de serem obtidas, inclusive por aqueles que estudam as literaturas africanas, os ministrantes optaram por apresentar fotos dos escritores e dos livros. A leitura quase sempre tinha dois momentos, 
um silencioso e individual e outro coletivo e oral, quer pelos ministrantes, quer pelos participantes. Já a confecção de propostas de atividades tinha por finalidade não só conferir o que os participantes compreenderam, como também a produção escrita usando outro gênero, tendo em vista o que estava sendo trabalhado pelo participante em sua prática docente. Assim, surgiram planos em que a partir de um conto seriam gerados poemas, histórias em quadrinhos, filmes, documentários, encenações teatrais, notícias de jornais, editoriais, reportagens, entre outros planejamentos. Percebemos que muitos são os discursos sobre a importância da leitura para a formação de cidadãos críticos, mas poucas são as iniciativas que promovem a capacitação de professores de ensino fundamental e médio, instrumentalizandoos a utilizar textos literários com o intuito de incentivar e oportunizar a efetiva leitura deles.

\section{UMA LÍNGUA QUE APROXIMA CONTINENTES E CULTURAS}

O que países separados por um ou dois oceanos de distância podem ter em comum? Em primeiro lugar, um idioma que une as culturas africanas à brasileira e à portuguesa. Somos ligados por laços que servem para nos lembrar de que a África não foi somente uma fornecedora de mão de obra escrava, trazida pelos colonizadores 
europeus, mas de seres humanos com História e histórias para contar. Se a Língua Portuguesa é o idioma presente nos documentos oficiais, ensinado nas escolas e usado na literatura dos Países Africanos de Língua Oficial Portuguesa (PALOP), há outra herança, que não é europeia e que possui papel importantíssimo em reforçar a identidade nacional de cada um desses países, muito bem representada pela ficção produzida pelos escritores africanos (CHAVES, 2009).

Pires Laranjeira (1995) ressalta que, durante o final do século XIX e a primeira metade do século XX, a Europa buscou nas literaturas africanas um certo exotismo. Ao invés disso, exploramos o humanismo que há nos textos, principalmente porque eles contemplam abundantemente os problemas humanos (coletivos, ideológicos, individuais, sociais e políticos), além de críticas ao colonialismo imposto no passado e ao poder estabelecido a partir das independências. Se a lei 10.639/03 estabelece diretrizes para o estudo da cultura e literatura afro-brasileiras, vimos nisso a chance de apreender mais a respeito de uma das nossas origens.

Tendo como princípio as obras críticas de especialistas como Carlos Everdosa (1985), Maria Aparecida Santilli (1985; 2007), Manuel Ferreira (1987), Pires Laranjeira (1995), Tânia 
Macedo \& Rita Chaves (2007) e Tânia Macedo \& Vera Maquea (2007), selecionamos as obras e os autores para a prática em sala de aula. Igualmente, a nossa experiência como ministrantes de cursos de extensão sobre o uso de textos de literaturas de língua portuguesa em sala de aula contou pelo que presenciamos e pelos relatos dos professores e suas práticas.

Com o propósito de propagar as literaturas africanas de língua portuguesa em sala de aula, procuramos contemplar em contos e contistas as dimensões geográfica (representantes dos cinco PALOP), temática e temporal (pré e pós-independência). Dessa forma, privilegiamos os contos que poderiam ser lidos em uma aula com o acompanhamento do docente, porque acreditamos na importância da função desempenhada pelo mediador, tanto na leitura quanto na compreensão, ao solucionar os problemas manifestados no ato de ler. Os autores contemporâneos selecionados são, em grande maioria, ainda vivos e continuam produzindo. Ao seguir o proposto por Cecília Bajour (2012, p. 27), pautamo-nos pela "[...] escolha de textos vigorosos, abertos, desafiadores, que não caiam na sedução simplista e demagógica, que provoquem perguntas, silêncios, imagens, gestos, rejeições e atrações". 
A partir das leituras e discussões entre os participantes (docentes da Educação Básica da rede pública de ensino da região de abrangência da UFFS) e estudantes de Letras e os dois coordenadores (ministrantes do projeto), realizamos a seleção dos contos para serem trabalhados nos encontros. Preocupamo-nos, da mesma maneira, com uma grande gama de temas: preconceito racial, colonialismo, infância, condição feminina, miséria, pois são tópicos estimados pelos escritores devido à vivência adquirida, assim como possuem certo apelo à faixa etária dos alunos da Educação Básica.

No que diz respeito à seleção, representando Angola temos: "O drama de vavó Tuturi", de Jofre Rocha (1980); "Velho Pedro", de Arnaldo Santos (1981); "Nos tempo de miúdo", de Boaventura Cardoso (1982); "Fronteira de asfalto", de José Luandino Vieira (2007); “Nós choramos pelo cão tinhoso", de Ondjaki (2007) e "Passei por um sonho", de José Eduardo Agualusa (2013). De Cabo Verde, "Caís do Sodré té Salamansa", de Orlanda Amarilis (1985) e "Tabus em saldo", de Dina Salústio (1999). Guiné Bissau contou com "O hóspede", de Andrea Fernandes (2010). Já Moçambique teve em "Indivíduo preto", de João Dias (1952); "As mãos dos pretos" e "Nós matamos o cão tinhoso" de Luís Bernardo Honwana (1980); "A derradeira noite da viuvez de Maria", 
de Nelson Saúte (1999); "O cego estrelinho", "Nas águas do tempo" e "Na esteira do parto", de Mia Couto (2003) suas narrativas. Finalizando com "Fé-em Deus", de Olinda Beja (2011), de São Tomé e Príncipe. A obra Imitação de Sartre \& Simone de Beauvoir, de João Melo (2004), escritor angolano, terá a experiência relatada, pois foi o único livro escolhido para ser lido integralmente.

\section{UM ITINERÁRIO DO CONTO NOS PALOP}

Para que haja um sistema literário, é imprescindível uma imprensa. Contudo, ela só surgiu no século XIX, nas seguintes datas: 1842 em Cabo Verde; 1845 em Angola; 1854 em Moçambique; 1857 em São Tomé e Príncipe e 1879 em Guiné-Bissau. Inicialmente havia o Boletim Oficial com legislação, notícias oficiais (governo), eventualmente contos, crônicas e poemas. Depois, surgiram jornais e revistas (principalmente por meio de associações culturais e recreativas), e algumas obras literárias como Nga Muturi, de Alfredo Troni, e Scenas d'África, de Pedro Félix Machado, ambas de 1882 e publicadas em folhetim, em Portugal. Há, também, O escravo, de José Evaristo de Almeida (FERREIRA, 1987; LARANJEIRA, 1995; SANTILLI, 1985).

Após a Conferência de Berlim (1884-1885), que dividiu o continente em áreas de influência europeia, Portugal viu-se 
obrigado a voltar-se para o interior de suas colônias. Nesse contexto, surge uma literatura colonial, tal como apresenta Pires Laranjeira (1995, p.26),

[...] significa a literatura escrita e publicada, na maioria esmagadora, por portugueses de torna-viagem, numa perspectiva de exotismo, evasionismo, preconceito racial e reiteração colonial e colonialista, em que a visão de mundo, o foco narrativo e as personagens principais eram brancos, colonos ou viajantes, e, quando integravam negros, eram estes avaliados superficialmente, de modo exógeno, folclórico e etnocêntrico, sem profundidade cultural, psicológica, sentimental e intelectual.

Retomando uma discussão do final dos anos de 1980, a respeito da visibilidade das literaturas africanas de língua portuguesa, José Carlos Venâncio (1992) afirma que elas foram mantidas na marginalidade por uma crítica portuguesa ao dizer "que tais literaturas, em parte ou no seu todo, eram desprovidas de valor estético e que os críticos literários, ao bajulá-las, traíam a causa da literariedade e, pior ainda, acabavam por prestar um mau serviço àqueles que por ventura tivessem valor" (VENÂNCIO, 1992, p. 25). Dessa forma, com pouco espaço em Portugal e pouquíssima divulgação fora de seus países de origem, a literatura dos PALOP demorou a ganhar espaço e reconhecimento fora 
da África. Manuel Ferreira (1987), Maria Aparecida Santilli (1985) e Pires Laranjeira (1995) destacam o papel que as antologias, os jornais e as revistas tiveram nas origens e difusão dessa produção literária. Somente nos anos de 1990 é que esse panorama se modificou.

Diferentemente das ex-colônias portuguesas em África, que passaram por duas guerras (de libertação e civil, muito recentes e com marcas indeléveis ainda na contemporaneidade), o Brasil não tem a memória viva da opressão colonial de Portugal, em virtude de nossa independência terocorrido no início do séculoXIX. Aocontrário dos PALOP, não temos pessoas (intelectuais, guerrilheiros) que passaram e enfrentaram os problemas advindos do colonialismo português, assim como pouquíssimos (até raros) relatos sobre a nossa independência, de modo que somos levados a acreditar que ela se deu de forma pacífica e consensual.

Entretanto, temos alguns problemas semelhantes: fome, miséria, exploração de todos os tipos, preconceito social e racial. O texto literário nos apresenta maneiras distintas de mimetizar e enfrentar essas mazelas. Existe tal força em textos curtos como "A mão dos pretos", de Luís Bernardo Honwana, que a catarse gerada pela história permanece em 
nossa memória por um bom tempo. O questionamento, as diferentes versões (com o mesmo teor de inferiorização do negro) nas respostas para a mesma pergunta intrigam tanto o narrador quanto o leitor. O gesto final da mãe e a falta de compreensão da criança indicam que ainda há espaço para a ingenuidade em meio ao racismo imposto pelo sistema colonial.

Russel Hamilton (1999, p.16) afirma que "A partir dos anos 40, nas duas colônias portuguesas, grupos relativamente pequenos, porém significativos, de intelectuais e escritores negros, mestiços e brancos uniam-se sob a bandeira do anticolonialismo". Se em Angola, Cabo Verde e Moçambique ocorreu a formação de uma literatura que representava os nativos, em Guiné-Bissau e São Tomé e Príncipe houve uma representação quase inexpressiva na prosa de ficção desse período.

No caso angolano, os prosadores de destaque no período compreendido entre o Movimento dos Novos Intelectuais de Angola (MNIA) e a Independência incluem nomes como: Agostinho Neto, Antônio Cardoso, Arnaldo Santos, Boaventura Cardoso, Castro Soromenho, Costa Andrade, Jofre Rocha, José Luandino Vieira, Pepetela e Uanhenga Xitu, entre outros. No século XXI, os dois nomes de maior 
reconhecimento são: José Eduardo Agualusa e Ondjaki. Há uma tradição contística desde a década de 50, de tal forma que

as narrativas curtas, quando se apresentam em dada obra, reforçam o aspecto de coletivo plural tão importante naquele momento histórico. [...] Já as narrativas curtas, principalmente nas dimensões que ganham no universo ficcional angolano - apresentandose na materialidade do livro como um conjunto - configuram-se como partes estelarmente fragmentadas de um corpo único que se tenta recompor a partir de seus pedaços. (PADILHA, 2011, p.25)

Esse diálogo que ocorre entre a tradição oral angolana e a narrativa escrita, visível nas histórias curtas publicadas desde os anos 50 no país, é aprofundado por Laura Cavalcanti Padilha em Entre voz e letra (2011), trabalho derivado de sua tese de doutorado.

Cabo Verde, tal como aponta Maria Aparecida Santilli (2007), tem uma tradição de revistas que revelaram autores e difundiram a literatura do país, tais como: Claridade (1936), Certeza (1944) e Ponto e Vírgula (1983). Na primeira, destacamse os nomes de Baltazar Lopes e Manuel Lopes; na segunda, Gabriel Mariano, Manuel Ferreira, Orlanda Amarílis e Teixeira de Souza; na última, temos em Dina Salústio e Germano de Almeida, dois dos mais conhecidos fora da nação. 
Abdulai Silla, que possui um romance publicado no Brasil, Andrea Fernandes, Julie Agossá Djomatin, Olonkó e Uri Sissé são escritores ligados ao nome da única editora privada de Guiné-Bissau, a Ku Si Mon, que não existe mais. Com isso, há poucas possibilidades de se publicar obras, restando, quase que exclusivamente, ao governo a responsabilidade de difundir a literatura guineense.

Em Moçambique, antes da década de 40, havia uma reduzida produção literária, mas é nela que surge a prosa de ficção no país (HAMILTON, 1999; SAÚTE, 2007). Jornais e revistas foram um suporte muito importante na formação de um incipiente sistema literário, tal como Candido (1997) concebeu, pois disseminaram autores e obras (contos e poemas, principalmente, além de crítica literária e cultural), numa colônia em que poucos tinham a capacidade de ler, com um público leitor ainda menor e quase sem incentivo cultural, visto que não havia editora alguma. Portanto, boa parte dos textos literários (contos, romances e poesia) foi publicada depois da independência e da criação da AEMO (Associação dos Escritores Moçambicanos). João Dias e Carneiro Gonçalves são dois exemplos de autores que não tiveram sua obra publicada enquanto eram vivos.

Augustos dos Santos, Ilídio Rocha, Ruy Guerra, Sobral dos Santos e Vergílio de Lemos são os pioneiros a terem 
textos publicados na década de 40. Carneiro Gonçalves, João Dias e Luís Bernardo Honwana apareceram no período compreendido entre os anos 50 e 60. Após a independência, Mia Couto é o escritor mais conhecido do público brasileiro, mas Nelson Saúte, Ungulani Ba Ka Khosa e Paulina Chiziane também foram publicados no Brasil.

A partir da independência, em Moçambique, a narrativa curta transformou-se no gênero predileto, pois, segundo Ana Mafalda Leite (2012, p.214), "o conto se adapta e se revela como a prática narrativa mais adequada, tendo em conta os seus estreitos laços com a oralidade, mais acessível à edição e à leitura e, muitas vezes, à representação teatral". Entre os anos 40 e 70 (que antecedem a independência) os textos literários tiveram um papel de ferramenta para manifestar a violência sofrida no período colonial. Depois de 75, a literatura permanece como "[...] um dos instrumentos de questionação deste mesmo processo e uma das pedras angulares na construção de uma identidade nacional" (SAÚTE, 2007, p.18).

Apesar de Albertino Bragança ser o prosador mais reconhecido de São Tomé e Príncipe, são as poetas Conceição Lima e Olinda Beja que têm obras publicadas em nosso país, visto que a prosa ainda não tem a mesma força que a poesia nas ilhas. 
Percebemos duas heranças nas literaturas africanas de língua portuguesa. A primeira, e mais antiga, é oral e local, tal como destaca Lourenço do Rosário (2009, p.11), quando afirma que "a transmissão oral é a forma que os nacionais utilizam na passagem de vários saberes de geração a geração. [...] As narrativas, mais do um gênero literário, são um verdadeiro repositório do universo cultural, filosófico, religioso, moral e até político das comunidades". A segunda é da língua do colonizador, transformada em instrumento de resistência e luta, desempenhando uma função primordial ao ser usada oficialmente em documentos, na educação formal e nos textos literários, destacada por Chaves (2009).

Contos, fábulas, lendas, em que a presença de animais da fauna, seres da natureza, espíritos e símbolos sobrenaturais destas sociedades e dos seus antepassados, das transformações que os mesmos viveram, ainda hoje são transmitidos para as futuras gerações conforme ressalta Rosário (2009). A passagem da oralidade à escrita envolveu a valorização e a apropriação da cultura oral, o uso de vocábulos e expressões das línguas autóctones, a (re)escritura do passado colonial, a (re)descoberta e (re)apropriação do folclore nativo. Para Ribeiro (2008, p.96), desde o final do século $X X$ "os PALOP têm oferecido ao mundo [...] um novo paradigma de produção cultural". 
Além do grande intercâmbio cultural (muitas vezes despercebido ou ocultado) que há entre África, América e Europa, há também a língua portuguesa que as une. Apesar da imposição do idioma oficial aos nativos africanos e americanos, esse contato proporcionou o surgimento de diferentes expressões literárias nas ex-colônias e o acréscimo de novas palavras e expressões à língua portuguesa. Assim, a literatura (entre outras artes) contribui para a propagação das culturas locais, que poderiam ser apagadas de outra forma. Com isso, a língua do colonizador passa a preservar as mundivivências das sociedades originárias.

\section{IMITAÇÃO DE SARTRE \& SIMONE DE BEAUVOIR: UM EXEMPLO DE LEITURA}

Em nossos encontros (como mediadores de leitura e professores de literatura) primamos pelo diálogo constante entre texto e leitor com o intuito de que as diferenças de linguagem, as referências históricas, a cultura popular, visto que a história recente de diversos conflitos, como a guerra pela independência e a guerra civil, não sejam empecilhos para a compreensão do texto, mas auxiliem na percepção de que diversas etnias moldaram estes povos, contribuindo, cada uma delas, diferentemente para esse amálgama cultural, que é cada nação africana. A literatura tem também 
a missão de promover esse conhecimento que quase foi extinto pela colonização ao impor uma língua e uma cultura como oficiais (CHAVES, 2009; SANTILLI, 1985).

A Lei 10.639/03 aumentou a visibilidade e aguçou a curiosidade pelas literaturas africanas de língua portuguesa. Contudo, ainda temos uma dificuldade, já elencada por Tania Macêdo e Vera Maquêa (2007, p.75), que destacaram "as difíceis condições de difusão do livro africano de língua portuguesa no circuito internacional e até mesmo lusófono". Isto quer dizer que há uma procura, mas a oferta (ou seria melhor dizer disponibilidade) é pequena, pois tanto estudantes quanto pesquisadores de áreas como Antropologia, Ciências Sociais, História, Letras e professores da Educação Básica não conseguem adquirir obras de referência, muito menos textos literários. A grande maioria das obras nunca foi editada no Brasil, e mesmo em suas nações ou em Portugal não tiveram mais de uma edição.

A partir da proposta de familiarização de estudantes de Letras e professores da Educação Básica com contos de autores africanos em língua portuguesa, no dia 02 de outubro de 2014 foi discutido na íntegra pelo grupo presente o livro Imitação de Sartre \& Simone de Beauvoir (2004), do escritor angolano João Melo (1955). O livro é composto por 
dez contos que tematizam predominantemente relações de casais ambientadas na Angola recém-independente, expondo as contradições de uma comunidade politizada emergente, mas que tem dificuldades em superar uma concepção de sociedade organizada por um sexismo conservador. Embora autor e obra fossem desconhecidos do público participante, foram criadas expectativas motivadas pelo título, que remete ao casal de filósofos franceses existencialistas. Os contos foram debatidos um a um, seguidos de breves comentários a respeito das impressões de leitura, das dificuldades ora encontradas e da viabilidade de trabalho em sala de aula.

Quanto aos elementos que chamaram a atenção do grupo, destacam-se: as distinções da ortografia e do vocabulário em relação ao português brasileiro; as referências intertextuais que compõem a obra; e, por fim, os saberes veiculados, sobretudo sobre a história recente de Angola, ignorada pela maior parte dos presentes.

Se não há familiaridade dos leitores com textos de variações europeia ou africana da língua portuguesa, de imediato há um estranhamento do leitor brasileiro com a grafia de certas palavras, como, por exemplo, "facto", "fenómenos" e "húmida". Ainda que fosse possível o reconhecimento da maior parte das palavras, a partir da 
comparação com a grafia correspondente no português brasileiro, eventualmente a pronúncia era motivo de dúvida, o que exigia esclarecimentos dos professores mediadores.

O mesmo embaraço com variações não-brasileiras da língua portuguesa provocou dificuldades com o vocabulário. Considerou-se, nesse caso, as palavras ou expressões comuns entre Portugal e Angola como, por exemplo, "fato" (terno), "miúdos" (crianças) e "osgas" (lagartixas). Expressões próprias ou gírias de Angola também mereceram a atenção do grupo, como nas seguintes ocorrências: "funje" (pirão com farinha de milho ou de mandioca), "calundus" (mau humor e irritabilidade), "mujimbos" (boatos). Percebemos com isso que há pouco diálogo entre as duas grandes áreas dos cursos de Letras, Linguística e Literatura, ao se considerar os poucos trabalhos que aproximam a linguagem literária da linguagem cotidiana e os substratos linguísticos para auxiliar os estudos literários no que diz respeito à variante africana da língua portuguesa. Comumente, nos textos não-brasileiros de língua portuguesa editados no Brasil, há glossários ou notas de vocabulário que somente dão o significado das palavras.

Horácio (1988) já defendia o caráter dulce et utile da poesia, que permanece atual especialmente nas reflexões teóricas sobre a literatura a ser trabalhada nas escolas para 
um público infantojuvenil. Neste caso, a leitura dos contos, motivada pelo propósito do curso em fomentar o debate sobre a viabilidade e as possibilidades de trabalho com os textos literários em sala de aula, propiciou também o aprendizado sobre aspectos da independência de Angola.

Esses saberes não são constituídos por datas e nomes célebres, mas pela vivência das personagens ao retratar os desafios, a expectativa e as desilusões pós-independência. Em "Até que a morte os juntou”, é narrada a intensa paixão de jovens guerrilheiros do MPLA que, após a guerra, foram estudar na União Soviética. Embora seja expressa no texto apenas pela sigla, a referência ao Movimento Popular de Libertação de Angola incita a curiosidade para que sejam buscadas maiores informações sobre os grupos políticos que protagonizaram a revolta armada pelo fim da dominação portuguesa.

No mesmo conto, é mencionado como inusitado o nascimento do primeiro filho do casal em Leningrado quando ela estudava Química, e ele, Relações Exteriores. A criança, "um filho soviético... / Um soviético negro..." (MELO, 2004, p.22-23), é tratada como uma raridade, comparada no texto com o escritor russo Alexandre Puskhin (1799-1837), supostamente negro também, embora essa 
informação seja dada como ignorada pelo discurso oficial. Tanto a possibilidade de estudos na União Soviética quanto a referência a Puskhin não são aspectos principais da narrativa, mas contribuem para que se tenha contato com outras histórias, outras culturas e outras realidades sociais.

A politização de personagens engajadas com os ideais da campanha de independência de Angola está presente neste conto, e também na voz dos protagonistas de "Sexo e violência", "Imitação de Sartre e Simone de Beauvoir" e "O estranho caso da Doutora Umbelina". Destaca-se, aqui, no entanto, a personagem Frederico, do conto "Querida Maria", que argumenta, frente à insatisfação de Maria, sua noiva, a defesa do governo independente e da inclinação ao socialismo:

Não é bem assim, meu amor. Não generalizes. Não confundas a árvore com a floresta!...". Acariciava-Ihe o queixo com doçura. "O que é que tu querias? Sabes quantos alfabetizados os tugas nos deixaram?, quantos licenciados? Governar um país não é fácil... o importante é que somos independentes, somos nós mesmos, como dizia o poeta. Aliás, reconhece lá isso, as coisas já foram bem piores... (MELO, 2004, p.44)

Maria, por sua vez, morava com a mãe e tinha dois filhos de Rui, seu esposo, que, com os conflitos de 1975, fugiu 
para Lisboa. Sem intenções de sair de Angola, acabou por relacionar-se com Frederico. Em dez anos, ela finalmente resolve aceitar o quarto pedido dele para viverem juntos. $\mathrm{E}$ embora a narrativa enfatize a intensa ligação sexual que os une, o foco do texto está na hesitação de Maria em ir ao encontro do noivo para as festas de réveillon às vésperas da mudança. No entanto, Maria não entendia Frederico:

No fundo (ou nem tão no fundo assim...), tinha a exacta noção de que era uma pequena-burguesa. Antigamente já vivia bem, não era como alguns que se servem dos cargos conquistados à custa da luta do passado para, afinal, se transformarem em numa nova burguesia, tão arrogante quanto ignorante. (MELO, 2004, p.45)

Essa acusação que a personagem faz ressoa em outros contos do mesmo livro. O aburguesamento de exguerrilheiros na máquina estatal é retratado, por exemplo, nos protagonistas dos contos "Crime e castigo", "Fuligem" e "O fato azul escuro". Isso permitiu que se tivesse acesso a situações contraditórias e nada maniqueístas da sociedade angolana. "Crime e castigo", inevitavelmente, remete ao título do romance homônimo de Fiódor Dostoiévski (18211881), mas aqui apresenta o dilema de um ex-combatente que foi beneficiado pela "politiquice": prestes a ser nomeado embaixador, quem ele levaria para ser sua embaixatriz? 
Lemba, companheira da época de guerrilha, com quem tinha três filhos, ou Rita, mulata da capital que usava cinco perucas e ia à praia com salto alto?

Várias referências a teóricos e artistas chamaram a atenção na leitura dos contos, como as menções a Marx, Engels, Puskhin, Barthes, Freud e Woody Allen, por exemplo. O próprio título do livro já apresenta referências explícitas. Entretanto, para quem esperava a abordagem de questões filosóficas houve certa decepção, pois Sartre e Beauvoir são mencionados como o casal que mantinha um relacionamento aberto e vivia em apartamentos separados. No conto "Imitação de Sartre e Simone de Beauvoir", narrado por Pedro, ele e a esposa Ana passam por uma crise em virtude da recorrente infidelidade conjugal do esposo:

Vês como estou?, perguntas. Mas é outra pergunta que me estilhaça o cérebro: como é que alguém que se pretenda revolucionário pode tratar assim a sua mulher? Eu respondia, cinicamente: a revolução foi feita pelos revolucionários disponíveis (citação de Brecht). Nessa altura, eu tinha começado a dormir fora de casa. Na impossibilidade de me arrancares as vísceras, tu quebravas a loiça. O socialismo começa dentro de casa! choravas, com todo o peso da lógica, que sabias inútil. Marxista de merda! É isso o teu marxismo?!... A tais perplexidades, eu opunha aquilo a que 
poderíamos chamar, provavelmente, a humanização dos clássicos: sabes que o próprio Marx comia todas as empregadas domésticas que lhe apareciam pela frente?... O coitado de Engels, depois, é que tinha de perfilhar os frutos dessas uniões... Por falar em frutos: por que que essas citações, digamos assim, heterodoxas dos pais do marxismo me deixavam sempre com um sabor de múcua podre na boca? (MELO, 2004, p.59-60)

A sexualidade é tema recorrente nos contos do livro, associada frequentemente ao machismo de uma sociedade que cinicamente evoca, quando conveniente, as tradições africanas de poligamia que entram em choque com valores morais resgatados pela politização das personagens. Em "Sexo e violência", por exemplo, é narrada uma "história tragicômica", em que o narrador-protagonista, casado, está envolvido em um "pentágono amoroso" ao relacionar-se com Manuela, que é casada com Simão, e também mantém relacionamentos extraconjugais com Fernando, médico cubano.

Por exemplo: se antes disso eu jamais me tinha preocupado com o Simão, o marido de Manuela, passei a experimentar em relação a ele um duplo sentimento de pena e culpa; pena por ele estar longe, na frente de combate, enquanto a sua querida esposa, em Luanda, disparava 
em leque [...]; e culpa por ele estar justamente na frente de combate, arriscando a vida para que nós, os calcinhas e os internacionalistas, the pudéssemos comer a mulher à vontade (em diversos momentos, cheguei a perguntar-me se minha atitude não seria contra-revolucionária?). (MELO, 2004, p.53)

A literatura oferece um exercício de alteridade, de permitir a experiência de se colocar no lugar do outro e compreendê-lo. No excerto acima, o próprio narradorpersonagem questiona-se a respeito, estendendo seu ponto de vista ao leitor, que é motivado tanto a se colocar no lugar das personagens, quanto a relacionar a situação narrada de forma análoga com a sua própria vida. Obviamente os contos de João Melo abordam especificidades culturais e históricas, mas também permitem a identificação na medida em que apresentam experiências e referências comuns ao público do curso, em uma cidade de pouco mais de 15.000 habitantes no noroeste do Rio Grande do Sul.

Causou surpresa e interesse na leitura dos contos algumas referências ao Brasil. As duas primeiras estão nos textos de apresentação do livro: são uma citação indireta a Monteiro Lobato sobre a importância dos livros para a construção de um país, e a outra é a comparação de aspectos da técnica 
narrativa de João Melo com a obra de Rubem Fonseca. Em ambos os casos, a surpresa se justifica porque o exemplar do livro utilizado no projeto foi editado em Luanda, portanto volta-se para o público angolano, mas ainda assim menciona os escritores brasileiros de modo que nos permite inferir que sejam conhecidos por lá, enquanto os escritores angolanos não sejam, na mesma medida, divulgados no Brasil.

Nos contos, uma breve menção está em "Querida Maria”, a respeito das economias de Frederico para a reforma do apartamento e a compra de mobília nova: "no Brasil, com as ajudas de custo; em vez de torrar nos copos, aproveitei..." (MELO, 2004, p.42). Outro registro está no conto "Imitação de Sartre e Simone de Beauvoir": "há muito tempo, por exemplo, li uma entrevista de um fazendeiro brasileiro que morava com quatro mulheres na mesma casa" (MELO, 2004, p.61), como argumento para a tese de que ao homem, para além das tradições africanas, é intrínseca a necessidade de ter várias parceiras sexuais. Por fim, há duas menções, no mesmo conto, à poesia de Jorge de Lima, quando o narrador, dirigindo-se à esposa, afirma que ela saíra nuinha do interior do poema do brasileiro. Há uma referência aqui ao célebre poema “Essa negra Fulô" (1929), em que é explorada, entre outros temas, a sensualidade da mulher negra. Revelou-se 
surpreendente, nesse caso, a possibilidade de (re)descoberta da obra de um dos mais importantes - ainda que sem a devida visibilidade - poetas brasileiros do século $X X$, justamente a partir da leitura de um livro angolano.

\section{CONSIDERAÇÕES FINAIS}

Incentivamos a valorização das literaturas africanas de língua portuguesa, porque há, entre outros fatores, a semelhança com a nossa em questões históricas. Há matéria suficiente e concreta para estudo, assim como obras que merecem atenção, tanto por parte de estudantes quanto de professores, por abordarem temas relevantes para o trabalho nas escolas. Ao proporcionar a conscientização sobre temas que são constantes também em nossa realidade: o machismo, a violência doméstica e familiar, a exploração, por exemplo, tratamos o distante como próximo.

Mesmo com tanta riqueza, as literaturas africanas de língua portuguesa raramente são abordadas como objeto de estudo na Educação Básica no Brasil. Dessa forma, ao divulgar a literatura e mostrar que há qualidade estética nos textos, ajudamos a quebrar pré-conceitos e valorizar o seu estudo e apreciação por parte de jovens leitores.

Tentamos demonstrar que para a literatura não há diferenças ou preconceitos. Não se pega um livro porque 
o escritor é branco ou negro. Lê-se pelo prazer de ler, pelo conteúdo apresentado. Não há como não se emocionar com histórias como "Nós matamos o cão tinhoso", de Luís Bernardo Honwana, e a homenagem de Ondjaki em "Nós choramos pelo cão tinhoso". Em ambos, o ambiente infantil e escolar remete-nos à inocência ainda não perdida pelos personagens e por nós leitores de textos literários.

\section{REFERÊNCIAS}

AMÂNCIO, Iris Maria da Costa; GOMES, Nilma Lino; JORGE, Miriam Lúcia dos Santos (2014). Literaturas africanas e afro-brasileira na prática pedagógica. 2.ed. Belo Horizonte: Autêntica.

BAJOUR, Cecília (2012). Ouvir nas entrelinhas: o valor da escuta nas práticas de leitura. São Paulo: Pulo do gato.

CANDIDO, Antonio (1997). Formação da literatura brasileira. Belo Horizonte: Itatiaia.

CHAVES, Rita (2009). Por um mar navegam as mesmas palavras. IN: BRAGANÇA, Albertino et al. Contos africanos dos países de língua portuguesa. São Paulo: Ática.

COSSON, Rildo (2011). Letramento Literário. 2.ed. São Paulo: Contexto.

EVERDOSA, Carlos (1985). Roteiro de literatura angolana. Luanda: União dos Escritores Angolanos.

FERREIRA, Manuel (1987). Literaturas africanas de expressão portuguesa. São Paulo: Ática.

HAMILTON, Russel (1999). "A literatura dos PALOP e a Teoria Pós-Colonial". Via Atlântica, 3, São Paulo, dez.

HORÁCIO (1988). "Arte poética”. In: ARISTÓTELES; HORÁCIO; LONGINO. A poética clássica. 3.ed. Jaime Bruna (Trad.). São Paulo: Cultrix. 
LARANJEIRA, Pires (1995). Literaturas africanas de expressão portuguesa. Lisboa: Universidade Aberta.

LEITE, Ana Mafalda (2012). Oralidades \& escritas pós-coloniais: estudos sobre literaturas africanas. Rio de Janeiro: EDUERJ.

MACEDO, Tânia; CHAVES, Rita (2007). Literaturas de Língua Portuguesa: Marcos e Marcas - Angola. São Paulo: Arte \& Ciência.

; MAQUÊA, Vera (2007). Literaturas de Língua Portuguesa: Marcos e Marcas - Moçambique. São Paulo: Arte \& Ciência.

MELO, João (2004). Imitação de Sartre \& Simone de Beauvoir. Luanda: Edições Maianga.

PADILHA, Laura Cavalcanti (2011). Entre voz e letra: o lugar da ancestralidade na ficção angolana do século XX. 2.ed. Niterói: EdUFF, Rio de Janeiro: Pallas.

PAULINO, Graça; COSSON, Rildo (2009). "Letramento Literário: para viver a literatura dentro e fora da escola". In: ZILBERMAN, Regina; RÖSING, Tânia. Escola e leitura: velha crise, novas alternativas. São Paulo: Global.

RIBEIRO, Giselle Rodrigues (2008). "Vida escrita - um breve olhar sobre o conto africano contemporâneo". Revista Eletrônica do Instituto de Humanidades, 7(8) Out-dez, São Paulo. In http://publicacoes. unigranrio.com.br/index.php/reihm/article/viewFile/65/181. Acesso em 15.Mai.2015.

ROSÁRIO, Lourenço do (2009). Antologia do conto africano de transmissão oral. Alfragide: Galilivro.

SANTILLI, Maria Aparecida (2007). Literaturas de Língua Portuguesa: Marcos e Marcas - Cabo Verde: Ilhas do Atlântico em prosa e verso. São Paulo: Arte \& Ciência.

(1985). Estórias africanas: história e antologia. São Paulo: Ática.

SAÚTE, Nelson (Org.) (2007). As mãos dos pretos: Antologia do conto moçambicano. 3.ed. Lisboa: Dom Quixote.

VENÂNCIO, José Carlos (1992). Literatura versus sociedade. Lisboa: Veja. 
Demétrio Alves Paz é Doutor em Letras (PUCRS); Professor de teoria literária e literaturas de língua portuguesa na UFFS, campus Cerro Largo RS; professor do Curso de Graduação em Letras, com ênfase em literaturas de língua portuguesa; artigos publicados nas revistas Via Atlântica (USP), Abril (UFF), Signo (UNISC).E-mail:demetrio.paz@uffs.edu.br.

Pablo Lemos Berned é Doutor em Letras (UFF); Professor de teoria literária e literaturas de língua portuguesa na UFFS, campus Cerro Largo - RS; professor do Curso de Graduação em Letras; artigos publicados nas revistas UNILETRAS (UEPG), Todas as Musas (SP). E-mail:pablo.berned@ uffs.edu.br. 